\title{
O MEDO NAS CRIANÇAS DE CLARICE LISPECTOR
}

\author{
Carolina Luiza Prospero \\ Mestranda em Literatura - UNICAMP
}

Resumo: Neste trabalho, buscaremos investigar a temática do medo em contos de Clarice Lispector que tenham crianças como personagens principais. $\mathrm{O}$ medo está presente em muitas das narrativas da autora, assumindo um papel de destaque no desenvolvimento de suas histórias. No caso da infância, ele surge como resposta à prematuridade das descobertas que a autora impõe às suas personagens. Comparando os textos de Lispector com alguns dos mais famosos contos da literatura de horror - como William Wilson e $O$ gato preto, de Edgar Allan Poe esperamos esclarecer os elementos que aproximam e que afastam a autora deste gênero literário, investigando o seu papel nesta tradição.

Palavras-chave: Clarice Lispector; contos; crianças; medo; horror

Abstract: In this work, we seek to investigate the theme of fear in Clarice Lispector's short stories which include children as main characters. Fear is present in many of the author's narratives, taking on a distinctive role in the development of her stories. Regarding childhood, it appears as a response to the prematurity of the discoveries the author imposes on her characters. Comparing Lispector's texts to some of the most famous short stories in horror literature - such as Edgar Allan Poe's William Wilson and The Black Cat - we hope to clarify the elements that bring the author closer and further from this literary genre, investigating her role in this tradition.

Key-words: Clarice Lispector; short stories; children; fear; horror 


\section{Introdução}

A literatura de Clarice Lispector tem sido investigada sob os mais variados aspectos ao longo das últimas décadas. No entanto, pouco foi falado a respeito do medo. Este sentimento, presente em muitos de seus contos e romances, aparece freqüentemente como obstáculo para o mergulho em uma vida plena. As personagens claricianas não desejam entregar-se a ele, embora isso seja quase inevitável quando a vida se revela em toda a sua crueza e seu esplendor. A epifania observada nos contos de Lispector - que desvela os paradoxos e as sutilezas da existência humana - está sempre às voltas com o medo.

A relevância que esta temática assume na obra da autora sugere alguns questionamentos: qual o papel da literatura clariciana dentro da literatura de horror internacionalmente conhecida? Qual a importância do trabalho de Lispector com o medo para o desenvolvimento deste gênero literário no Brasil? A fim de nos aprofundarmos nessas questões, comparamos algumas das histórias claricianas estudadas a narrativas de autores tradicionalmente incluídos na tradição do horror, como é o caso de Edgar Allan Poe. As consciências atormentadas de suas personagens e a cuidadosa construção psicológica de que são feitas apresentam muitos pontos em comum com as personagens de Lispector. Contudo, evoluções temáticas como o nascimento da feminilidade e o medo da plenitude da existência colocam a autora em uma posição de vanguarda no tratamento do medo.

Uma observação cuidadosa nos mostra que a relação que o medo estabelece com as personagens varia de acordo com a etapa da vida em que elas se encontram. As personagens adolescentes, sempre à caça de respostas, estão mais preparadas para aceitar o novo mundo trazido pela revelação epifânica do que as personagens mais maduras. Estas últimas, amortecidas por um cotidiano monótono e sem sobressaltos propositalmente criado por elas, parecem ter uma maior inabilidade para lidar com a desestruturação. Neste trabalho, teremos como foco a infância, período de crescimento e descobertas. Através da exploração de tão árduo caminho, acompanharemos a dificuldade das pequenas protagonistas claricianas em amadurecer, observando seu confronto diário com o medo e com a dor. 


\section{O medo na infância}

Ainda que não sejam numericamente predominantes como personagens dos contos de Lispector, as crianças têm uma participação bastante relevante nas narrativas da autora. Não é à toa que já em sua primeira incursão literária - o romance Perto do Coração Selvagem (1998) - a protagonista Joana é retratada em diversos momentos da infância antes que sejam expostos os seus dilemas de adulta. A representação de sua meninice não poderia jamais ser vista como gratuita: ela tem o claro propósito de construir os alicerces de sua personalidade irrequieta, justificando as atitudes que a mulher Joana um dia teria. Embora os contos geralmente não comportem este tipo de desenvolvimento processual das personagens (dado o seu caráter mais sintético), em alguns deles poderemos vislumbrar flashes da influência que o episódio infantil retratado exercerá no futuro da protagonista. Essa oscilação entre diferentes idades mostra-se especialmente útil para compreendermos as variações do impacto epifânico em cada uma das etapas da vida, sempre enredadas em sentimentos como o desejo e o medo.

No entanto, é importante ressaltarmos que a idéia da infância, na obra de Lispector, tem muito menos a ver com a idade real das protagonistas do que com uma forma de encarar a existência humana. De acordo com a teoria de Agamben (2005), a infância é o período da vida em que o homem se abre para a experiência. Esta experiência não está ligada a uma noção de tempo decorrido - como é comumente interpretada na atualidade - mas sim a um modo de estar no mundo, sujeitando-se ao novo, ao incerto, ao imprevisível. Um leitor atento perceberá que as personagens claricianas que passam pela revelação epifânica acabam por encarar o mundo desta maneira, mesmo que somente por alguns instantes. Contudo, a consciência despertada para o mundo e para o interior do ser faz com que, simultaneamente à ousadia de encarar o desconhecido, o sujeito também se sinta às voltas com o medo e com a dor. A abertura para a experiência dos contos de Lispector jamais se apresenta como um momento de tranqüilidade.

Em todos os contos da autora protagonizados por crianças, há certas características das personagens infantis que se mantêm. Observá-las com atenção é traçar um perfil da criança clariciana, desvendando as impressões da autora sobre o 
papel destes pequenos seres no mundo. Dentre estas qualidades infantis essenciais, destaca-se a inocência. $\mathrm{Na}$ visão de Lispector, as crianças trazem consigo uma plena inocência a respeito das nuances e complexidades do ser humano. Este estado de ignorância - e entendamos aqui este termo como um desconhecimento, conforme proposto por Kierkegaard (1962) - só é rompido através do movimento epifânico que, no caso dos contos protagonizados por crianças, ocorre ainda prematuramente na infância. Porém, fica clara a admiração da autora pela inocência infantil, comumente associada à inocência animal. Seu discurso parece sempre carregar uma espécie de "nostalgia da inocência" que se ancora no pesar da necessária ruptura pela qual o adulto já passou. Há a certeza de que, uma vez vislumbrada a plenitude, não existe a possibilidade do retorno.

Uma outra qualidade das crianças dos contos de Lispector, que também é ligada ao comportamento animal, é a instintividade. Assim como os bichos, o comportamento dos pequenos seres humanos é regido por uma carga de instintos inatos ao homem; suas ações são guiadas por sentimentos básicos como a possessividade, a curiosidade ou o medo. A falta de filtros freqüentemente associada ao comportamento infantil aproxima ainda mais a criança do animal, atribuindo a ambos uma incontrolável selvageria. Esta característica é ressaltada principalmente através da comparação entre estas pequenas criaturas e os adultos dos contos de Lispector, dado que o adulto reprime e domestica quaisquer excessos em sua personalidade. Da mesma forma que a inocência, os instintos selvagens das crianças parecem fascinar a autora, tornando-se responsáveis por construir parte do movimento do texto.

\section{A menina Sofia}

Uma das crianças que melhor ilustra o modelo infantil clariciano é Sofia, do conto Os desastres de Sofia. O título é retomado, por Clarice Lispector, do romance infantil da Condessa de Ségur. Diz Dinis Pestana (2005) que

A Sofia dos Desastres, da Condessa de Ségur, faz muitas asneiras, é castigada, arrepende-se, faz outras asneiras, e o ciclo recomeça. Naturalmente, $[\ldots]$ aprende o suficiente para romper esse ciclo, ganhar juízo, não sendo conseqüentemente imoral terminar num happy end de 
felicidade reencontrada, um padrão inevitável num livro infantil, que tem que transmitir otimismo e fé nos valores estabelecidos.

Pestana propõe uma relação entre infância, imaturidade, treino, lições de vida, aprendizagem de padrões. Alguns destes elementos também estarão presentes nas desventuras da Sofia clariciana, embora a autora jamais compartilhe dos objetivos tradicionais das clássicas narrativas infantis. Publicada pela primeira vez no volume $A$ Legião Estrangeira, de 1964, a história de Lispector tem como protagonista uma garota de nove anos que vive uma conflituosa relação com seu professor. Através da narração memorialista de Sofia, sustentada em impressões sobre o Outro e sobre ela mesma, presenciamos o momento de pura compreensão entre ambos, instante que força a menina a descobrir as angústias e dores do mundo adulto.

Seu professor - "gordo, grande, silencioso, de ombros contraídos" (LISPECTOR, 1983, p. 11) - é apresentado como um homem sobre quem os alunos pouco sabiam. Sofia logo confessa seu fascínio por aquela estranha figura: “E eu era atraída por ele. Não amor, mas atraída pelo seu silêncio e pela controlada impaciência que ele tinha em nos ensinar e que, ofendida, eu adivinhara" (idem). A partir desta constatação, a narradora-menina descreve vivamente a dinâmica de atração e repulsa que os une. Ela passa a atormentar diariamente o professor, acreditando que sua cruel insistência de criança o salvaria da opressiva vida adulta em que se aprisionara. A oposição entre estas duas idades do ser humano - que, de acordo com a teoria de Agamben (op.cit.), definem-se como formas distintas de vivenciar o mundo - se instaura, neste primeiro momento do texto, de forma contundente, embora posteriormente venha a ser dissolvida pela epifania da menina.

Sofia, "demônio e tormento" daquele misterioso homem de paletó curto e óculos sem aro, se reconhece ao longo de toda a história como um ser com vocação para a maldade. Este "reconhecimento da maldade" ecoa as traquinagens da Sofia de Ségur. A natureza sádica da personagem é enunciada por Yudith Rosenbaum (2006) em seu estudo sobre o conto. Para ela, "Sofia, cuja identidade negativa se afirma em todo o conto ("viver errado me atraía"), ataca o estrito princípio de realidade do professor, opondo-lhe sua "vadiação" e seu gosto pelo prazer de violar o instituído" (ibidem, p. 56). Rosenbaum destaca este gosto pela desobediência e pela provocação como 
elementos-chave da persona de Sofia, evidenciando sua selvageria infantil. Mais do que isso, a pesquisadora nota a presença de uma "ingenuidade perversa" em seu caráter, marca da infância que simboliza a mais pura inconsciência.

\section{O despertar para o mundo}

Rosenbaum coloca como 'linhas de força' do conto dois nascimentos em Sofia: o da escritora e o da mulher. Através da composição de um texto que subjuga a moral imposta pelo professor, a menina consegue do homem um gesto de amor, de admiração. Gesto, este, que ela renega, irritada pela ingenuidade daquele adulto que fora enganado por uma criança. Conforme a pesquisadora constata, "o texto, aos olhos de Sofia, é um monstro descontrolado, que ludibria as frágeis consciências” (ibidem, p. 62). É difícil para a garota acreditar que, apesar de tantas provocações, é a escrita o que desperta aquele homem de seu estado letárgico no mundo. Seu intenso sadismo, canalizado em criatividade literária, transforma-se em saber-se capaz de comover.

Neste sentido, é interessante lembrarmos a relação que Agamben (op. cit.) estabelece entre a infância e a linguagem. Para o filósofo, o período da infância é caracterizado pela abertura do ser humano à experiência, o que ocorre através do desenvolvimento da linguagem. Esta progresso se dá quando o homem supera a simples nomeação, pela qual se insere de forma básica na língua, e atinge um estágio de construção do discurso, impulsionado pelo aprendizado. Daí a afirmação de que "é na linguagem e através da linguagem que o homem se constitui como sujeito" (ibidem, p. 56). Conforme nota-se no caso de Sofia, a produção de um discurso no próprio espaço discursivo que é o texto acompanha a gradual sujeição da menina ao incerto, àquilo que foge totalmente de seu controle, como a manifestação de vida posteriormente encenada pelo professor. Assim, o processo de constituição identitária representado neste conto é firmado, fundamentalmente, através do processo de formação da linguagem.

Considerando estas duas gêneses propostas por Rosenbaum, podemos agora tocar no medo presente neste texto. Isso porque este sentimento se revela principalmente na cena em que a descoberta dessas duas vocações ocorre. Sofia, garota sem medo da transgressão e da maldade, é antes de mais nada atingida pela dor: 
sentimento que revela a percepção e o acolhimento da alteridade, assim como a decepção com relação a si mesma.

\begin{abstract}
Mas eu o exasperava tanto que se tornara doloroso para mim ser o objeto do ódio daquele homem que de certo modo eu amava. Não o amava como a mulher que eu seria um dia, amava-o como uma criança que tenta desastradamente proteger um adulto, com a cólera de quem ainda não foi covarde e vê um homem forte de ombros tão curvos. (LISPECTOR, 1983, p. 11)
\end{abstract}

A tentativa de proteger o adulto da submissão ao que quer que fosse, protegê-lo da covardia, leva Sofia a agir. Sua ação é desastrada. Sua ingenuidade, portanto, reside na ilusão de poder solucionar o problema, de poder ajudar um adulto que parecia tão perdido sem ela. Tem algo de onipotente este sentimento imaturo, infantil.

Além disto, Sofia é tomada de surpresa quando seu olhar se cruza com o do professor, sozinhos na sala de aula. A expressão alegre que ela trouxera do recreio, sua corrida de menina estabanada, tudo aquilo cessa no instante em que ambos se enxergam. A cena passa, então, a ser construída sob uma tensão crescente, sustentada principalmente no silêncio criado pelo encontro. Para isso, a autora usa frases curtas, cuidadosas, apreensivas. "Era a primeira vez que estávamos frente a frente, por nossa conta. Ele me olhava. Meus passos, de vagarosos, quase cessaram” (ibidem, p. 17). O receio da menina é simbolizado por uma gota de suor, que "foi descendo pelo nariz e pela boca, dividindo ao meio o meu sorriso" (ibidem, p. 18). A expressão fingida mostra-se, então, como uma forma de esconder do mundo o seu horror naquele instante: "Meu sorriso cristalizara a sala em silêncio, e mesmo os ruídos que vinham do parque escorriam pelo lado de fora do silêncio. Cheguei finalmente à porta e o coração imprudente pôs-se a bater alto demais sob o risco de acordar o gigantesco mundo que dormia" (idem). Este "mundo adormecido" é o da ação, da resistência, da afirmação da vida. Buscando fugir do encontro opressivo, Sofia atentava para o ambiente escolar, agora transformado em um ambiente imenso e assustador: "nunca havia percebido como era comprida a sala de aula; só agora, ao lento passo do medo, eu via o seu tamanho real" (idem). A troca de olhares e o pedido gélido do professor para que chegasse mais perto eram, para ela, aterradores. 
A pesquisadora Regina Pontieri já trata, em seu estudo sobre o livro A Cidade Sitiada, daquilo que chama de "a poética do olhar" na obra de Clarice Lispector. Para ela, o ato de olhar e o de comer mostram-se juntos no texto clariciano, configurando o olhar como uma espécie de "devorar" do Outro. Contudo, ao invés de uma separação entre aquele que vê/engole e aquele que é visto/engolido, a autora sugere que as idéias de 'possuir' e 'comer', “ao anularem a distância entre os pólos, impedem o fechamento de cada um em si mesmo" (PONTIERI, 1999, p. 23). A relação que se estabelece entre Sofia e seu professor parece ser firmada neste processo de deglutição através do olhar, no qual a imensa distância entre eles - criança e adulto - é minimizada através da compreensão de um universo em comum. O medo de Sofia é gerado justamente a partir da percepção da vida que existe no Outro, da fragilidade que ela não entende como pode existir na figura de um adulto. O pavor do sorriso, da esperança e do amor que faziam da existência um caminho tão errante e tortuoso. Esse medo se revela completamente através da "potência mágica do olhar", de acordo com o termo de Benedito Nunes (1995):

O que vi, vi tão de perto que não sei o que vi. Como se meu olho curioso se tivesse colado ao buraco da fechadura e em choque deparasse do outro lado com outro olho colado me olhando. O que era tão incompreensível como um olho. (...) Eu vi um homem com entranhas sorrindo. (...) Minhas costas forçaram desesperadamente a parede, recuei - era cedo demais para eu ver tanto. Era cedo demais para eu ver como nasce a vida." (LISPECTOR, op. cit., p. 21)

Notamos que o medo de Sofia se relaciona principalmente com a tensão entre a infância e a vida adulta. Contudo, Sofia ainda é uma criança de nove anos e não está pronta para as nuances da maturidade. Havia lhe sido dado o peso da descoberta do ser humano - porém, ela sabia que sua selvageria infantil não estava pronta para entender o Outro de forma tão honesta. Seu terror se agrava ainda mais ao se perceber confrontada não somente com um professor, mas com um homem, pois também a sua existência como mulher ainda não lhe havia sido revelada. “(...) vi que o professor era muito grande e muito feio, e que ele era o homem da minha vida. O novo e grande medo" (ibidem, p. 18). Observando a figura da narradora-menina sob estes aspectos, 
evidenciam-se as razões para o medo do riso e do amor que o professor ensaiava. Conforme nos diz uma angustiada Sofia, "ver a esperança me aterrorizava, ver a vida me embrulhava o estômago. Estavam pedindo demais de minha coragem só porque eu era corajosa, pediam minha força só porque eu era forte. 'Mas e eu?'” (ibidem, p. 21).

\section{O duplo}

Além do susto com a vida em sua forma mais crua e exposta, Sofia também se horroriza com a inesperada identificação entre si mesma e o professor. A garota constata, enfim, que a figura masculina de sorriso desajeitado à sua frente não representa nada além dela mesma, nada além da mesma matéria humana que ela, inevitavelmente, viria a se tornar. Podemos relacionar este intenso espelhamento com a temática do "duplo" presente em inúmeros contos de horror, como o William Wilson (1978) de Edgar Allan Poe. Nesta história, o protagonista é acompanhado desde a infância por uma espécie de cópia de si mesmo que o imita nas vestimentas, no nome e na data de nascimento. Suas impressões de criança deste duplo mostram-se contraditórias, oscilando entre a fascinação e a repulsa:

$\mathrm{Na}$ verdade, é difícil definir, ou mesmo descrever meus verdadeiros sentimentos para com ele: formavam um amálgama extravagante e heterogêneo - uma animosidade petulante que não era ainda ódio, estima, ainda mais respeito, uma boa parte de temor e uma imensa e inquieta curiosidade. É supérfluo acrescentar, para o moralista, que Wilson e eu éramos os mais inseparáveis camaradas. (POE, 1978, p. 92)

Conforme o protagonista cresce e assume um comportamento cada vez mais desregrado, a presença inesperada do duplo passa a ser sempre motivo de intenso horror. Estudos como o de Azevedo (2003) vêem o duplo de William Wilson como a consciência do protagonista, sempre buscando desafiá-lo e conduzi-lo para longe do mal. É interessante como as impressões sobre o duplo neste conto podem ser igualmente relacionadas a Os desastres de Sofia, já que a relação que se estabelece entre o professor e a aluna sustenta-se na dualidade entre fascínio e repulsa. Conforme nos explica a 
narradora, “tornara-se um prazer já terrível o de não deixá-lo em paz. O jogo, como sempre, me fascinava" (op. cit., p. 12). Mais do que isso, podemos observar na insistência terrível de Sofia o pesado dever de salvar aquele homem de si mesmo. "Era de se lamentar que tivesse caído em minhas mãos erradas a tarefa de salvá-lo pela tentação" (ibidem, p. 13).

Já vimos que a obra de Lispector tem como característica particular a extensão da compreensão do Outro para a de si mesmo. Nesta narrativa, isso se torna evidente a partir do momento em que os olhares de ambos se encontram e a menina vê no professor um estranho e embrionário amor. Sofia percebe, através do sorriso do homem, que não existiria salvação para ela. Afinal, eles eram parte da mesma matéria humana, ela um ser em construção do que ele já se tornara. Configura-se entre eles a imagem do duplo - eram opostos e iguais. Esta terrível constatação revela-se um dos principais momentos do conto:

na minha impureza eu havia depositado a esperança de redenção nos adultos. A necessidade de acreditar na minha bondade futura fazia com que eu venerasse os grandes, que eu fizera à minha imagem, mas a uma imagem de mim enfim purificada pela penitência do crescimento, enfim liberta da alma suja de menina. E tudo isso o professor agora destruía, e destruía meu amor por ele e por mim. Minha salvação seria impossível: aquele homem também era eu" (LISPECTOR, 1983, p. 23)

A partir da identificação, Sofia foge do horrendo futuro que era o professor, extremamente abalada: “... e de repente, com o coração batendo de desilusão, não suportei um instante mais - sem ter pegado o caderno corri para o parque, a mão na boca como se me tivessem quebrado os dentes. Com a mão na boca, horrorizada, eu corria" (idem). Quando finalmente a fuga cessa, a menina, esgotada, despeja no mundo toda a sua maldade. Ela se re-afirma como o feio, o ruim, o sujo - e sente amargamente que tivera que ser amada porque somente ela estivera ali para salvar aquele homem. Nota-se, neste fechamento da narrativa, a evocação de um elemento presente em várias outras narrativas claricianas: o amor pelo pequeno, pelo baixo, pelo grotesco da vida. $\mathrm{Na}$ apresentação da segunda parte do volume A Legião Estrangeira, a autora nos 
confessa seu imenso apego pelo "lixo": "além do mais, o que não presta sempre me interessou muito. Gosto de um modo carinhoso do inacabado, do malfeito, daquilo que desajeitadamente tenta um vôo e cai sem graça no chão” (apud ROSENBAUM, op. cit., p. 129). Inúmeros estudiosos chamam a atenção para a presença do menor na obra de Lispector, como Rosenbaum - que classifica este recurso como uma "estética do negativo" - e Arêas (2005), em sua análise sobre o livro de contos mais polêmico e questionado da autora, A via crucis do corpo. A própria Sofia assume: "tudo o que em mim não prestava era o meu tesouro" (LISPECTOR, op. cit., p. 25).

Imersa na descoberta dos paradoxos da existência, Sofia revela-se maldita e santa ao salvar um homem pelo amor. Num paralelo com o próprio enredo da narrativa, podemos dizer que, ao final, o "tesouro escondido" de cada uma das personagens é revelado ao leitor - mesmo este tesouro sendo o pouco, o insuficiente, o incompleto. $\mathrm{O}$ processo de desvelar o oculto do homem através do medo e da dor talvez possa ser visto como uma das grandes forças-motrizes da obra de Lispector.

\section{A verdade do animal}

Em oposição ao espírito puramente infantil de Sofia, o conto A Legião Estrangeira, publicado também no volume homônimo de 1964, apresenta ao leitor a rigidez de Ofélia. Embora narrado por uma mulher adulta, este conto traz como protagonista uma criança séria, acusativa e opressora. A curiosa relação entre esta mulher sem nome e a menina é lembrada quando a narradora ganha de presente de Natal um pequeno pinto. $\mathrm{O}$ animal é o elo de ligação entre o momento presente e o momento passado da narradora, no qual a garota tem uma intensa e controversa participação.

No início do conto, a mulher faz uma detalhada descrição dos sentimentos que o recém-chegado pinto desperta em cada um dos membros da sua família. Segundo ela, “sentimentos são água de um instante" (LISPECTOR, 1983, p. 97), e assim o leitor acompanha a desajeitada mudança de laços que a família passa a estabelecer com o animal. Despertados para uma bondade ansiosa, o marido e os quatro filhos da mulher aos poucos vão sentindo o amor que nasce pela criatura, embebendo-se também da opressiva responsabilidade de quem ama. O pinto, cada vez mais assustado, pia constantemente. "Eu não sabia sequer onde cabia tanto terror numa coisa que era só 
penas" (idem) - diz a narradora, desajeitada e aflita. Mas o horror existe em todas as coisas que nascem e a consciência dos seres vivos vem, segundo ela, "do susto profundo" (ibidem, p. 100). A mulher afirma que "só mãe resolve o nascimento", e a íntima certeza deste fato é o que leva seus filhos a pedirem que ela se torne a mãe do pinto. Buscando curar o sofrimento do animal por um processo que desconhecia, embora intuísse, ela finalmente assume a terrível e necessária tarefa de salvá-lo pelo amor.

Esta introdução mostra diversos aspectos relevantes para a interpretação do texto como um todo. Primeiramente porque define, de acordo com a concepção da autora, o tipo de relação que se estabelece entre homens e animais, salientando a aproximação natural entre eles. Não é segredo que os bichos despertavam imenso interesse em Clarice Lispector. Ao longo de sua vida teve cachorros, coelhos e até uma macaquinha, todos eles transformados em personagens de suas histórias. Além disso, cavalos, búfalos, galinhas e baratas ajudam a compor um universo animal que parece infindável nos contos da autora. Na maior parte das vezes, a presença destes seres em suas narrativas serve como contraponto à desconcertante complexidade humana: as personagens da autora invejam a simplicidade dos bichos, sustentada por sua bestialidade instintiva. Para ela, o animal sente o amor ou o medo de forma pura, incorrupta, fazendo-o por exclusiva necessidade de sua natureza. Esse imediatismo visceral surpreende as personagens humanas por sua própria impossibilidade - embora tenhamos os mesmos comportamentos básicos de sobrevivência, sentimentos como a culpa surgem de maneira inevitável no indivíduo, afastando-o irremediavelmente do sonho de uma ignorância reconfortante. Somente as crianças, imbuídas de inocência e atitudes impensadas, são capazes de assemelharem-se ao ideal dos animais.

Em segundo lugar, a angustiante jornada de amor que o pinto desperta na família pode ser diretamente comparada à relação que se estabelece entre Ofélia e o outro pinto em um momento passado. Alguns pontos importantes, como o amor quase instantâneo que a inocência do animal desperta e o medo do mundo inerente a todas as criaturas vivas, estão presentes nas duas narrativas que compõem o conto. No entanto, veremos que os desfechos dessas histórias paralelas serão completamente opostos, o que evidencia a imaturidade da garota diante de tão complexa situação quanto entender as várias e ambíguas faces da existência humana. 


\section{A menina Ofélia}

A primeira narrativa serve de pretexto para que a narradora conte ao leitor a história de Ofélia, filha de uma casal bastante reservado e com ares hindus que morava no mesmo prédio que ela. Altiva e crítica, aquela menina de oito anos passa a freqüentar a casa da mulher, opinando insistentemente sobre sua vida e suas falhas. A autoridade de Ofélia incomodava-a profundamente, como se todos os seus atos e pensamentos fossem sempre equivocados; com uma alma adulta em corpo de criança, a garota impunha sua opressiva presença à mulher, que não encontrava maneira de se livrar daquela pequena torturadora. Até que um dia esta mulher adquire um pinto. Ofélia ouve com espanto o fraco piar que vem da cozinha e, desconfiada, vai ao encontro do bicho. É nesse momento que a narradora percebe que uma mudança se opera lentamente na menina.

Ao escutar o piar do animal, a pequena e controlada Ofélia sente-se invadida por um obsessivo desejo de ter. Os sentimentos de cobiça e inveja a tomam por inteira - de relance, a narradora contempla uma "dissimulada sagacidade, nos olhos a grande tendência à rapina” (ibidem, p. 106). Em silêncio, ela observa a metamorfose que se faz na menina, contemplando a angústia de Ofélia em finalmente ver-se criança. "Mais e mais se deformava, quase idêntica a si mesma. Arrisco? deixo eu sentir?, perguntavase nela. Sim, respondeu-se por mim” (ibidem, p. 107). Segundo a teoria de Agamben (op. cit), aquela garota tão precocemente amadurecida, tão fechada à novidade e à incerteza, finalmente permitia-se sentir o verdadeiro sabor da infância. Embora amedrontada, Ofélia colocava-se completamente à disposição da experiência naquele instante. Abria-se para o desconhecido, cuidadosamente deixando-se viver.

A mulher então sugere à Ofélia que ela vá brincar com o pintinho na cozinha, embora emende: "mas só se você quiser" (ibidem, p. 108). A crueza de deixar tal escolha nas mãos da garota faz com que a narradora se sinta culpada, embora siga afirmando ao leitor que a decisão de abrir-se para o amor incondicional que um ser vivo demanda deveria pertencer unicamente a ela. Dessa forma, o medo da vida segue sendo um tema caro às histórias de Lispector, sempre aliado à solidão dessa experiência. 
Perplexa e assustada, Ofélia volta segurando delicadamente o animal. E é aí que se entrega completamente às doçuras de um amor infantil, intenso e sufocante. Desvelase em cuidados para o bicho, enquanto a mulher a contempla: "olhei-a, toda de ouro que ela estava, e o pinto todo de ouro, e os dois zumbiam como roca e fuso" (ibidem, p. 110). A entrega de Ofélia à sua infância recém-descoberta é um sopro de alívio para a esgotada narradora, que agora está certa de que a menina a libertará de seu jugo cruel e inoportuno, sua presença forçada na casa. Satisfeita, ela antecipa: "também minha liberdade afinal, e sem ruptura; adeus, e eu sorria de saudade” (idem).

No entanto, o final do conto surpreende pelo esmagamento da tão promissora alegria vinda do "renascimento" de Ofélia. Numa cena em que quase se pode sentir o silêncio, a menina encontra-se parada, incapaz de responder a qualquer pergunta feita pela mulher. Após o estranho pedido da garota para retirar-se, a narradora deixa a máquina de escrever e segue para a cozinha. É lá que vê o pinto no chão, morto. Fica claro, então, para ela que Ofélia assustara-se terrivelmente com os sacrifícios requisitados pelo amor. Suplicante, a narradora lamenta a triste entrega da criança ao medo, a deserção do caminho que a colocaria em contato com o mais essencial da vida:

Ofélia, tentei eu inutilmente atingir à distância o coração da menina calada. Oh, não se assuste muito! às vezes a gente mata por amor, mas juro que um dia a gente esquece, juro! a gente não ama bem, ouça, repeti como se pudesse alcançá-la antes que, desistindo de servir ao verdadeiro, ela fosse altivamente servir ao nada. Eu que não me lembrara de lhe avisar que sem o medo havia o mundo. Mas juro que isso é a respiração. (LISPECTOR, 1983, p. 111)

Assim, a narrativa se fecha com um movimento brusco do amor para a maldade, que culmina na glória de um íntimo perdão. A brutalidade do ato de Ofélia - o sacrifício de um ser inocente - demonstra sua incapacidade de criança em lidar com o verdadeiro sacrifício exigido pelo amor: a responsabilidade da salvação. A partir do momento em que as crianças claricianas percebem que o entendimento do viver é paradoxal em sua própria essência, conduzindo à liberdade e, ao mesmo tempo, à obrigação de salvar, há uma recusa violenta em aceitar a totalidade desta experiência. Isso pode ser notado também no conto analisado anteriormente: tanto Sofia e sua selvageria infantil quanto 
Ofélia e seu mergulho antecipado na seriedade dos adultos amedrontam-se diante da complexidade da existência que lhes é exposta, buscando qualquer rota de escape possível. No caso da primeira, a fuga é literal, numa corrida que tenta deixar para trás tudo aquilo que fora prematuramente contemplado; já para a segunda, escapar é sufocar o ser que lhe despertara para o imenso horror de viver, é encobrir o amor mais puro através de um ato cru de maldade. A narradora ainda tenta salvar Ofélia através do perdão, ela que já enfrentara anteriormente o medo que nasce do extremo bem-querer. Mas a menina já não se encontra mais ali, e sua redenção ocorre somente no âmbito pessoal daquela mulher.

\section{A perdição e o perdão}

Alguns elementos importantes deste conto permitem que se trace um paralelo entre ele e uma das histórias mais conhecidas de Edgar Allan Poe, a macabra $O$ Gato Preto. O primeiro deles é a presença de um animal que funciona como motor de todo o enredo. No conto de Lispector, temos o pequeno e frágil pinto; já no conto de Poe, surge um imponente e sagaz gato preto. Este último é considerado o bicho de estimação favorito do narrador, embora sua casa abrigasse muitos outros. Tal fascinação pelos animais é explicada por ele como decorrente de seu caráter excessivamente doce e terno, similar à natureza bondosa destas criaturas. No entanto, veremos que sua supostamente amorosa personalidade passa a sofrer uma deformação com o passar dos anos - ele mesmo afirma que se tornava, "dia a dia, mais taciturno, mais irritadiço, mais indiferente aos sentimentos dos outros” (POE, 1978, p. 42). Esta mudança, forçadamente maniqueísta, ganha contornos muito mais sutis no texto de Lispector, já que a indiferente Ofélia descobre, em poucos minutos, a existência simultânea de sentimentos antagônicos como o amor e o ódio no ser humano.

Outro momento em que os textos se entrecruzam é quando o sacrifício do animal amado acontece. No conto de Poe, o narrador, em um de seus acessos de fúria, cruelmente enforca o gato no galho de uma árvore. Vil e indigno, este terrível ato levará o narrador à sua perdição. A partir daí, uma série de acontecimentos estranhos começa a ocorrer, como o incêndio que dizima sua casa e o gato semelhante ao outro que passa a segui-lo. Mas só fica claro para aquele homem que todos estes acontecimentos se 
relacionam ao seu crime quando o amaldiçoado gato revela a um grupo de policiais o corpo da mulher do narrador, emparedado junto ao bicho no porão da casa. Já o pinto morto por Ofélia não conduz a garota a nenhum tipo de desdobramento maldito; as conseqüências desta atitude provocada pelo medo resumem-se à retração de sua liberdade espiritual e de seu conhecimento sobre a plenitude da vida. No entanto, para a autora, o embotamento da alma é um dos piores castigos. A cena final do conto nos deixa em suspenso quanto ao destino de Ofélia, embora insinue que ela renegará a experiência que teve por um longo tempo. Nesse sentido, Lispector provavelmente concordaria com a afirmação de Simenon citada no estudo de Jean Delumeau: "o medo é um inimigo mais poderoso que todos os outros" (apud DELUMEAU, 1989, p. 19).

\section{Conclusão}

Tendo por base as análises de $A$ legião estrangeira e Os desastres de Sofia realizadas neste trabalho, podemos notar que as protagonistas infantis de Lispector se entregam completamente ao medo e ao confronto com a complexidade da vida. Parece que aquilo que se apresenta como imaturidade é, ao contrário, a intuição da plenitude, paradoxal em sua essência. Seu "estado de inocência" as distancia de padrões, modelos, normas sociais. Elas estão mais próximas do ego que os adultos. O medo vivido por essas garotas é o primeiro passo do processo de negação que elas enfrentam após a revelação epifânica, que leva Sofia a uma ensandecida fuga e Ofélia ao assassinato de um inocente como ela. Nenhuma delas sabe lidar com o amor e com o ódio que, juntos, advém da compreensão. O medo, nesses dois contos, é plena proteção contra o sentir.

\section{Referências}

AGAMBEN, Giorgio. Infância e história: a destruição da experiência e a origem da história. Trad. de Henrique Burigo. Belo Horizonte: Ed. UFMG, 2005.

AREAS, Vilma. Clarice Lispector com a ponta dos dedos. São Paulo: Companhia das Letras, 2005. 
AZEVEDO, Estevão. A filosofia da composição em "Wiliam Wilson", de Edgar Allan Poe. 2003. Acesso em: 30 de abril de 2008. Disponível em: http://www.geocities.com/estevaoazevedo/williamwilson.html.

DELUMEAU, Jean. História do medo no Ocidente. São Paulo: Companhia das Letras, 1989.

KIERKEGAARD, Sören. O conceito da angústia. Tradução de João Lopes Alves. Porto: Editorial Presença, 1962.

LISPECTOR, Clarice. A Legião Estrangeira. 6a ed. São Paulo: Ática, 1983.

Perto do Coração Selvagem. Rio de Janeiro: Rocco. 1998.

NUNES, Benedito. O drama da linguagem: uma leitura de Clarice Lispector. 2. ed. São Paulo: Ática, 1995.

PESTANA, Dinis. Os Desastres de Sofia e as Estruturas do Acaso. 2005. Acesso em:

4 de dezembro de 2008. Disponível em: http://www.esenviseu.net/Principal/Actividades/URL/12/dinispestanaresumo.pdf.

POE, Edgar Allan. Histórias Extraordinárias. São Paulo: Abril Cultural. 1978.

PONTIERI, Regina. Clarice Lispector: uma poética do olhar. São Paulo: Ateliê, 1999.

ROSENBAUM, Yudith. Metamosfoses do mal: uma leitura de Clarice Lispector. São Paulo: Editora da Universidade de São Paulo: Fapesp, 2006. 